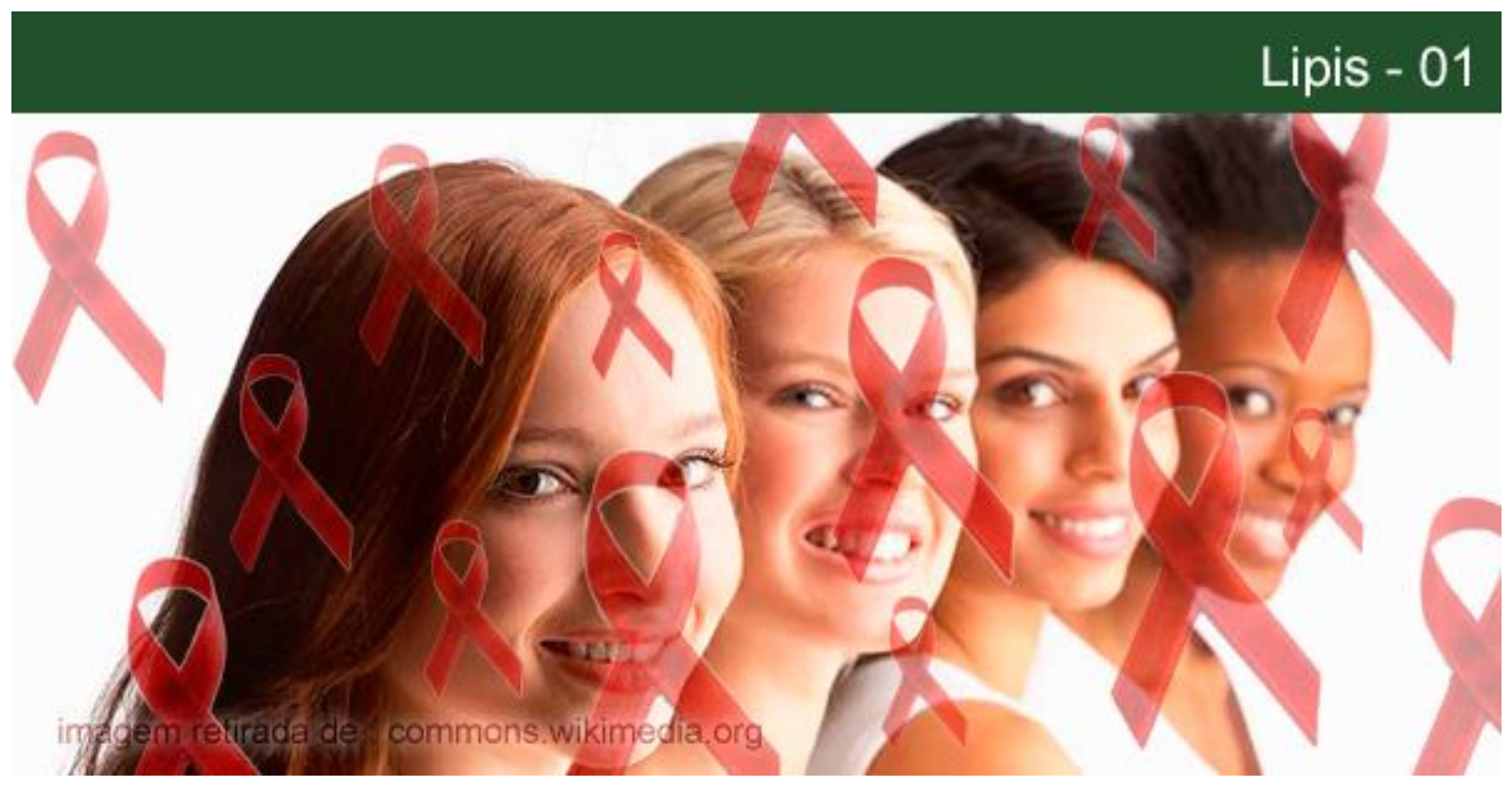

\title{
TRAUMA E FEMINILIDADE NA CLÍNICA COM MULHERES VIVENDO COM HIV/AIDS ${ }^{1}$
}

\section{Paula Affonso de Oliveira}

Psicóloga. Mestre em Psicologia pelo Programa de Pós-Graduação em Psicologia da Universidade Federal do Pará (PPGP/UFPA). Integrante do Laboratório de Psicanálise e Psicopatologia Fundamental da UFPA. Email: paulaoliveira.psi@gmail.com.

\section{Ana Cleide Guedes Moreira}

Psicóloga. Mestre e Doutora em Psicologia Clínica pela PUCSP. Professora do Programa de Pós-Graduação em Psicologia da Universidade Federal do Pará. Pesquisadora do Hospital Universitário João de Barros Barreto. Diretora do Laboratório de Psicanálise e Psicopatologia Fundamental da Universidade Federal do Pará. Pesquisadora da Associação Universitária de Pesquisa em Psicopatologia Fundamental. Pesquisadora do Laboratório Interdisciplinar de Pesquisa e Intervenção Social da PUC-Rio. Chercheur associé à l'Université Paris 7 Denis-Diderot. Membro da Réseau Internacional de Psychopathologie Transculturelle. E-mail: acleide@uol.com.br.

Resumo: O presente trabalho tem como objetivo discutir trauma e feminilidade no caso clínico de uma mulher vivendo com o HIV. Analisa-se fragmentos de caso de uma paciente inserida em um ciclo de violência, perpetrado pelo próprio marido, que culminou em sua infecção. Levanta-se a hipótese de que seu diagnóstico se configurou como traumático, atualizando o trauma originário, colocando-a frente ao território da feminilidade. Ao entrar em contato com o excesso pulsional característico desse território, sua própria finitude e a quebra de seus ideais, outra possibilidade de ordenação do sexual foi sendo construída. O trabalho clínico em um dispositivo psicanalítico possibilitou a narrativa da experiência traumática, lançando-a em um movimento de ressignificação do feminino.

Palavras-chave: Trauma. Feminilidade. Psicanálise.

\section{TRAUMA E FEMININITY IN THE CLINIC WITH WOMEN LIVING WITH HIV/AIDS}

\footnotetext{
${ }^{1} \mathrm{O}$ presente artigo é fruto da dissertação da primeira autora, intitulada "Entre a mulher e o feminino: uma leitura psicanalítica da feminilidade", defendida no Programa de Pós-Graduação em Psicologia da UFPA, sob orientação da segunda autora, com bolsa CAPES e auxílio a pesquisa do CNPQ Processo No: 404921/2012-4.
}

\section{POLÊM!CA $\mid$ LABORE (}

Polêmica - Revista Eletrônica da Uerj - Rua São Francisco Xavier, 524, $1^{\circ}$ andar

bloco D, sl.1001 • Tels.: +55 21 2334-4088/4087 • http://www.e-publicacoes.uerj.br/index.php/polemica/index http://www.labore.uerj.br • laboreuerj@yahoo.com.br 
Abstract: This paper aims to discuss trauma and femininity in the case of a person living with HIV. We analyze the case of a woman inserted in a cycle of violence perpetrated by her own husband, which culminate in her infection. The hypothesis is the traumatic diagnosis updated the original trauma and the territory of femininity. When in contact with the drive excess, characteristic of that territory, her own finitude and the breakdown of her ideals, another possibility for sexual ordination was possible. Clinical work in a psychoanalytical device enabled the narrative of the traumatic experience, initiating a process of subjective transformation.

Palavras-chave: Trauma. Femininity. Psychoanalysis.

A psicanálise nasceu para dar voz ao emergente e não para corroborar a tradição.

(Maria Rita Kehl, 2008).

Nos atendimentos clínicos realizados no hospital com pessoas vivendo com aids, frequentemente nos deparamos com mulheres submetidas ao que Kehl (2008) denomina padrão de feminilidade, ou seja, marcadas pelos ideais culturais que ditam às mulheres os papeis de mãe e esposa como principais, se não únicos, modos de subjetivação. Mulher fiel e mãe dedicada, são justamente esses ideais que muitas vezes se tornam insustentáveis diante da descoberta do diagnóstico positivo para HIV/aids, pois, se no imaginário social a aids ainda é a doença do outro, ela não é de qualquer outro, mas de mulheres promíscuas e prostitutas. Portanto, quando estas mulheres, mães e esposas, se descobrem contaminadas, descobrem também quebrados seus ideais e a imagem que tinham de si. Não raro, o diagnóstico produz nessas um insustentável sentimento de culpa, seja pela dificuldade em conceber sua própria contaminação, seja pela constatação de que os ideais não foram suficientes para protegê-las.

Duas são as principais consequências diante do conflito psíquico aí instalado: ou seu intenso sofrimento psíquico produz um quadro depressivo, no qual as intervenções da equipe multiprofissional frequentemente não são suficientes para conduzir a melhora de estado da paciente, vindo a falecer no hospital; ou as pacientes defensivamente apegam-se com mais força a estes ideais, em especial à maternidade, sustentando no casamento e nos filhos a possibilidade e o desejo de recuperação.

Mas seria este o destino inevitável da condição feminina no hospital? A escuta de algumas mulheres, insubmissas, por assim dizer, mostrou outros destinos possíveis. Dentre as quais, destaca-se o caso de Amanda, 40 anos, casada e mãe de dois filhos, acompanhava o marido, internado há duas semanas no hospital acometido por uma das muitas doenças oportunistas da aids.

\section{POLÊM!CA $\mid$ LABORE}


Durante o tempo em que permaneceu no hospital, Amanda narrou uma história, marcada pela violência, mas também pelo posicionamento diante de seu sofrimento, durante o atendimento psicoterápico realizado pela primeira autora, sob supervisão da segunda. Iniciou talvez pelo ponto mais alegre, seus filhos. Narrou seus nomes, a série em que estavam e o que iriam fazer em suas vidas. Ela, o marido e os dois filhos moravam no interior e sobreviviam da pesca, uma vida "normal", em suas palavras. Apesar de uma aparente ausência de demanda, suas expressões e seu jeito inquieto e angustiado despertaram na psicoterapeuta um incômodo com a suposta normalidade e a supervisão serviu para apontar a necessidade de questionar esse discurso. Nos atendimentos seguintes veio à luz uma história marcada pela violência perpetrada pelo marido, que culminou em sua contaminação.

A primeira fala além da normalidade inicial veio no segundo atendimento, quando expressou sua condição de pessoa vivendo com o HIV. Há cerca de um ano o marido adoecera, mas recusava qualquer forma de tratamento, somente após perder a audição é que procuraram uma Unidade de Saúde, na qual ele foi diagnosticado com aids. Amanda foi aconselhada a também realizar o teste. Segundo conta, no momento em que sentou na cadeira da sala da profissional para receber o resultado sentiu-se surda. De nada mais lembra até quando se percebeu sentada na beira da calçada, amparada por sua irmã. A narrativa do momento do diagnóstico foi repetida por Amanda algumas vezes, sem, contudo, lembrar-se do que lhe foi dito e sem conseguir falar do que sentiu ao receber seu resultado. Narrava os fatos, mas não os afetos.

Somente em um atendimento posterior, quando narrou um sonho que teve no hospital, começou a falar sobre o significado que o diagnóstico assumiu para si. E o que faltava na cena, trouxe nos sonhos. Nesse ela vagava de madrugada sozinha, em um corredor branco e escuro, com uma faca cortava os pulsos, mas não saia sangue, apenas um líquido amarelo. Indagada sobre o que era aquele líquido veio a resposta: "essa doença, aids, eu queria tirar tudo isso do meu sangue, só escorria isso".

A partir deste sonho foi aos poucos narrando sua história. Após o nascimento do segundo filho, o marido começou a passar mais tempo fora de casa, fugindo na madrugada para ir a festas. Frequentemente, ao voltar embriagado para casa, obrigava-a a manter relações sexuais com agressões ao menor sinal de resistência. Somente após o adoecimento do marido

\section{POLÊM!CA $\mid$ LABORE}


a situação começou a mudar, ao conseguir reagir às agressões, pois, segundo ela, "agora ele não podia mais contra mim".

Em um dos últimos atendimentos, a psicoterapeuta chegou à enfermaria e ela apressou-se em chamá-la para o corredor. Narrou então outro sonho no qual estava com os filhos e o marido andando por uma rua quando começava a chover muito forte, ela avistava uma casa, parecida com um castelo, pegava os filhos e corria com eles para lá, enquanto o marido ficava para trás, na chuva. Para ela, correr para a casa com os filhos era uma maneira de protegê-los e ela não ajudava o marido porque "ele não importa mais". Quando indagada do que ela queria protegê-los, ela falou que queria protegê-los de ter "essa doença".

A partir deste sonho, passou a questionar a vida com o marido, dizia sentir-se sua mãe, não esposa, pois depois da doença ele passou a agir "como um bebê". Permeada de ódio e culpa, ora dizia querer deixá-lo num rompante, ora queria organizar sua saída para que ele não ficasse só

No último atendimento, ao adentrar a enfermaria a terapeuta deparou-se com Amanda sentada arrumando uma sacola, o marido deitado no leito chorando ao seu lado. Não houvera atendimento há alguns dias porque ela havia viajado para resolver questões concernentes aos filhos e à sogra, conforme contara. Amanda levantou-se e disse para ele que a esperasse. Na sacada, lugar habitual dos atendimentos, ela contou a decisão de separar-se do marido, havia organizado a vinda da mãe dele para substituí-la e iria com os filhos, que já estavam na cidade, para a casa da irmã.

Narrou como havia entrado em contato com a mãe dele e que esta havia compreendido sua decisão, sabia "dos erros do filho". Mais cedo tinha contado a decisão para o marido, veio ao hospital somente para fazer isso e pegar algumas coisas que havia deixado antes de sair. Quando indagada a respeito dos dias que passou fora, relatou que teve muita ajuda da irmã, que a acolheu em sua casa, decidindo, enfim, afastar-se dele. Agradeceu as "conversas", disse que antes estava "sem rumo", mas agora sabia o que fazer, pediu licença e saiu. A psicoterapeuta permaneceu alguns momentos sentada na varanda, olhando-a enquanto Amanda se levantava, sorria e voltava para a enfermaria. Naquele mesmo dia deixou o hospital acompanhada da irmã, o que foi relatado pela sogra, dois dias depois. Deixou conosco parte de sua história e as inquietações que atualmente animam este trabalho.

\section{POLÊM!CA $\mid$ LABORE}


A história de Amanda, se não é única, por retratar o movimento de outras mulheres, pacientes e acompanhantes, que passaram pelo hospital durante o tempo em que se desenvolve esta pesquisa, apresenta um outro destino para a mulher. Mas não deixam de estar presente as marcas da submissão, passividade e dependência que, como descreve Torok (1975), são características de um destino propriamente feminino decorrente da inveja do pênis e, podemos acrescentar das relações assimétricas entre os gêneros na qual a mulher é relegada a uma posição inferior ao homem. Permeada por este padrão de feminilidade, Amanda mantém uma posição masoquista e de submissão ao marido violento e apresenta, em maior ou menor grau, as saídas descritas anteriormente, como podemos notar pelo estado depressivo a qual foi acometida após o diagnóstico, assim como a importância do ideal de mãe sustentando seu desejo de viver.

Segundo Faria (2004), cada sujeito ordena a questão sexual a partir de certos significados que são sempre mais ou menos precários, não havendo uma construção simbólica que recubra completamente a sexualidade. Logo, por não haver uma essência feminina ou masculina, os atributos próprios de um e de outro são sempre marcados por uma construção individual. É essa construção, perpassada pelos seus ideais e por todo um padrão de feminilidade vigente, que Amanda retrata ao narrar uma história na qual ser mulher consiste em ser submissa, mãe e esposa dedicada que, mesmo diante da violência do marido, precisa submeter-se. Uma mulher cuja normalidade é dividir-se entre as tarefas domésticas e o cuidado com os filhos, que compõem a obrigação feminina "por natureza", em um contexto inicial no qual a própria violência é naturalizada.

Na narrativa de Amanda, seu marido fugir de casa para festas e submetê-la às mais diversas formas de violência eram atributos masculinos, "coisa de homem", que seria sempre intrusivo, abusivo, ao qual a mulher precisaria aceitar submissa e passivamente. Não estamos aqui tão distantes do que Kehl (2008) aponta como o peso da cultura ocidental sobre a mulher, visto fortemente na maternidade, e a consequente posição de esposa, como única possibilidade identificatória, o que marca, em parte, as teses freudianas sobre a sexualidade feminina.

Segundo Freud (1931, [1996]), para alcançar a feminilidade, a menina, que nos primeiros anos da vida infantil é fantasiosamente um menino, precisa realizar o trabalho de abandonar seu primeiro objeto de amor, a mãe, em função do pai, e trocar sua zona erógena

\section{POLÊM!CA $\mid$ LABORE}


principal, do clitóris, órgão supostamente masculino, para a vagina, zona propriamente feminina.

O trabalho de abandonar a mãe e a satisfação clitoridiana estão relacionados ao deslocamento feito pela menina entre desejar o pênis e desejar um bebê como substituto do pênis. Temos neste último o cerne da sexualidade feminina adulta: sentindo-se castrada diante da diferença sexual, a menina buscaria compensar a sua ausência procurando em substitutos o falo perdido (FREUD, 1925 [2011]). O desejo de ter um filho, nesse sentido, seria, concomitantemente, próprio da sexualidade feminina e também fruto do eterno anseio masculino da mulher marcada pela inveja do pênis. Como consequência desta sexualidade invejosa, um Supereu mais débil, menor capacidade sublimatória e ciúmes - características que, podemos conceber, demonstrariam uma maior predisposição psíquica para a vida doméstica, em detrimento da vida pública.

O continente negro da psicanálise freudiana assim o é, em grande parte, pela lente sobre qual foi visto, uma lente fálico-edípica, não poderia antever nada mais que a inveja “desse órgão visível e interessante do menino" (MCDOUGALL, 1997, p. 4). Entretanto, não se trata aqui de acatar a hipótese de uma misoginia em Freud. Assim como retirar a lente masculina da sexualidade feminina é preciso, também o é retirar a lente do anacronismo e fazer uma leitura da época. Menos que um caminho universal, a sexualidade feminina adulta marcada pela maternidade parece traduzir a única identificação permitida à mulher de acordo com os ideais de seu gênero na época de Freud: a identificação com a posição de mãe.

A história narrada por Amanda é marcada pela usual posição dada à mulher e, consequentemente, ao feminino na cultura ocidental, até o momento do diagnóstico. No caso de Amanda, o diagnóstico configurou-se como traumático, impondo-a duas constatações trágicas para o humano: a finitude do Eu e o sexual, trazendo consigo associações mortíferas do imaginário social da doença, no qual ter aids é "estar condenado", como afirma Amanda, a definhar lenta e dolorosamente.

O diagnóstico fere a fantasia de onipotência narcísica, reinscrevendo o trauma psíquico, ao colocar o sujeito diante do sexual. O contato com o sexual provoca uma tensão entre o Eu e os ideais, gerando intenso sofrimento, além de um movimento cíclico de culpa e preconceito (CECCARELLI, 2000). No caso do diagnóstico de HIV há culpa inconsciente

\section{POLÊM!CA $\mid$ LABORE}


pela ruptura dos ideais identificatórios que são, como no caso de Amanda, constituídos pelo padrão de feminilidade contemporâneo.

O diagnóstico de Amanda a coloca justamente de frente com o sexual, ou seja, com seus desejos inconscientes, seja no imaginário de uma expressão da sexualidade que rompe com a moral vigente - porque aids é doença de prostitutas e de mulheres promíscuas -, seja pela irrupção de afetos que não poderiam ser narrados por romperem com seus ideais, especialmente o de esposa e mãe, tão fortemente arraigados quando relata a "normalidade" de sua vida.

O ideal de mulher submissa, parceira e mãe fiel, que assim permanece diante de diversas agressões e demonstrações dessa impossibilidade, continua presente até o último golpe, a contaminação, que apresenta enfim o atestado de falência destes ideais que o diagnóstico traumático impõe e, consequentemente, a ruptura com as representações construídas acerca do feminino e masculino, do que é ser mulher e ser homem.

Foi a experiência traumática trabalhada em um dispositivo psicanalítico que possibilitou Amanda traçar um percurso marcado pela ressignificação dessas representações. Ao afirmar que a condição humana é sempre traumática, Freud aponta para a finitude e imperfeição que marcam o humano (BIRMAN, 2001). O trauma, produzido pelo excesso de energia que rompe as barreiras do sistema psíquico, coloca o sujeito frente a uma situação de desamparo, no qual o trauma originário é atualizado.

O território do trauma, portanto, é marcado pelo excesso pulsional e pela impossibilidade de representação que ganha corpo na teorização freudiana a partir da virada metapsicológica, no qual, ao propor o conceito de pulsão de morte, demonstrou os limites de um trabalho analítico calcado somente na associação livre. A pulsão de morte aponta para o limite da interpretação, limite que demarca o campo de representação do referencial fálicoedípico que não recobriria o excesso pulsional irrepresentável da mesma.

Segundo Birman (2001, p. 227), a teorização acerca do um dualismo pulsional da segunda tópica na teoria freudiana permitiu o primeiro passo em direção ao conceito de feminilidade originária, pois na origem da vida humana haveria este território traumático marcado pela invisibilidade, pela impossibilidade de representação, enfim, pelo excesso pulsional, "constitutivo da existência humana". Tece-se assim a relação entre trauma e

\section{POLÊM!CA $\mid$ LABORE}


feminilidade: a feminilidade é justamente o território do trauma primordial, do masoquismo, da fragmentação, da finitude e imperfeição.

Contudo, este precisaria ser recalcado e o referencial fálico-edípico erigir-se-ia como uma defesa frente às vivências originárias. A posição masculina, característica da organização infantil, em ambos os sexos, calcada no referencial fálico, sustentar-se-ia a partir do recalque da feminilidade originária, erguendo-se de maneira defensiva frente a essa. Para tanto, ao masculino seria atribuída a marca da perfeição na figura de um falo sempre idealizado. E, na descoberta da diferença anatômica entre os sexos, essa defesa fálica teria seu principal momento de consolidação, porque o falo passa a ser a medida de ambos os sexos, marcando a oposição entre o falo e sua ausência, a posição castrada.

Enquanto a pulsão de vida apontaria para esse inconsciente organizado pela representação, a pulsão de morte estaria fora deste campo. No primeiro, campo do representável e da visibilidade, a figura do falo como organizador da subjetividade permitiu revelar o próprio inconsciente. Contudo, nas origens, essa representação ainda não se faz presente, algo escapa ao domínio do falo: uma força pulsional não se liga ainda com o registro das representações, é puro excesso não representável (BIRMAN, 2001).

Diante dessas considerações, levantamos como hipótese que o trauma ocasionado pelo diagnóstico de HIV atualizou o trauma originário, logo, colocou Amanda frente ao registro da feminilidade, ocasionando uma queda de seus referenciais identificatórios e de seu ideal de esposa e mãe, conforme mantinha até o momento. Com isso, precisou construir uma nova "gramática subjetivante", nas palavras de Birman (2001, p. 239), ou seja, uma nova organização para haver-se com o excesso pulsional.

Afinal, renegociou sua posição frente ao outro: se antes permanecia numa posição masoquista, emblemática da neurose, ao ter esvaziado o referencial fálico diante do trauma e entrar em contato com o sexual e sua própria finitude, enfim, com a feminilidade, pode defrontar-se com a alteridade. Como afirma Arán (2006, p. 214), este encontro com o estranho em si e no outro significa um "abalo nos limites do eu", que demonstra como "[...] a sexuação é alguma coisa que se produz a cada momento, pois sempre se faz provisoriamente a partir do encontro com o outro".

Diante do território da feminilidade, outra possibilidade de ordenação entre masculino e feminino foi sendo construída. O sonho do castelo, em que por fim admite seus afetos

\section{POLÊM!CA $\mid$ LABORE}


ambivalentes para com o marido, parece ter sido emblemático ao permitir finalmente dizer "este lugar eu não quero mais". Estaria ela falando somente da permanência no hospital ou, para além da estada nas enfermarias, Amanda dá testemunho também do lugar de mulher que ela possuía e que agora rejeitava? Nossa hipótese é que, ao recusar esse lugar, não somente não queria mais estar no hospital, mas também não queria essa posição feminina vigente.

O que sustentamos, com a discussão de fragmentos deste caso, é a importância de escutar o sujeito do inconsciente na instituição, oferecendo um espaço, no caso do atendimento de mulheres vivendo com aids, em que possam ser construídas outras possibilidades para além do padrão de feminilidade marcado pela submissão, passividade e os ideais de mãe e esposa, ao experimentarem a provisoriedade desses referenciais identificatórios e possibilidade de ressignificação dos mesmos.

Por fim, se o feminino marca a psicanálise desde o seu surgimento, com a escuta das histéricas - mulheres que com seu corpo em transe ocuparam os espaços antes negados a elas pela construção cultural de uma suposta natureza feminina - é também por meio dele que se inicia um novo horizonte para pensar a diferença.

A feminilidade originária nos defrontaria com uma outra relação com o falo, esvaziado de qualquer marca de perfeição, possibilitando outras produções de sentido e concebendo novas formas de subjetivação não mediadas completamente pelo registro fálico (BIRMAN, 2006). Se as subjetividades organizadas por esse registro são apenas uma manifestação defensiva de uma modalidade de subjetivação, então cada sujeito cria gramáticas subjetivantes para lidar suas forças pulsionais, indicando a necessidade de uma leitura singular da sexualidade humana.

É preciso, afinal, conceber que o trabalho da psicanálise não é de "corroborar a tradição", como descreve Kehl (2008, p. 317) empreendendo a leitura da organização simbólica de um momento sócio-histórico, mas sim, frente às mudanças sociais, de "dar voz ao emergente" analisando os efeitos das mesmas na emergência possível de uma nova ordem simbólica.

\section{Referências}

ARÁN, Márcia. O avesso do avesso - feminilidade e novas formas de subjetivação. Rio de Janeiro: Garamond, 2006.

\section{POLÊM!CA $\mid$ LABORE}


BIRMAN, Joel. Gramáticas do erotismo: a feminilidade e as suas formas de subjetivação em psicanálise. Rio de Janeiro: Civilização Brasileira, 2001. 2006. Genealogia do feminino e da paternidade em Psicanálise. Nat. hum. [online], v. 8, n. 1, p. 163-180,

CECCARELli, Paulo Roberto. Sexualidade e preconceito. Rev. Latinoam. Psicopat. Fund., v. III, n. 3, p. 1837, 2000.

FARIA, Michele Roman. O que é uma mulher? Respostas clínicas ao problema do feminino. Psyche (São Paulo), v. 8 n. 13, p. 101-108, jun. 2004.

FREUD, Sigmund. Algumas consequências psíquicas da diferença anatômica entre os sexos (1925). Obras completas: O eu e o id, "autobiografia" e outros textos (1923-1925). São Paulo: Companhia das Letras, 2011, Vol. 16.

Sexualidade feminina (1931). O futuro de uma ilusão. Edição Standard Brasileira. Rio de Janeiro: Imago, 1996, Vol. XXI.

KEHL, Maria Rita. Deslocamentos do feminino. 2. ed. Rio de Janeiro: Imago Ed., 2008.

MCDOUGALL, Joyce. As múltiplas faces de eros - uma exploração psicoanalítica da sexualidade humana. São Paulo: Martins Fontes, 1997.

TOROK, Maria. O significado da "inveja do pênis" na mulher. In: CHASSEGUET-SMIRGUEL (Org.). A sexualidade feminina - novas pesquisas psicanalíticas. Rio de Janeiro: Editora Vozes, 1975, p. 153-185.

Recebido em: 19/07/2016.

Aceito em: 31/08/2016.

\section{POLÊM!CA LABORE}

